\title{
Frequent deletion of the CDKN2A locus in chordoma: analysis of chromosomal imbalances using array comparative genomic hybridisation
}

\section{KH Hallor, ', J Staaf', G Jönsson ${ }^{2}$, M Heidenblad', F Vult von Steyern ${ }^{3}$, HCF Bauer ${ }^{4}$, M IJszenga $^{5}$, PCW Hogendoorn ${ }^{6}, \mathbf{N}$ Mandahl', K Szuhai ${ }^{5}$ and F Mertens'}

'Department of Clinical Genetics, Lund University Hospital, Lund SE-22I 85, Sweden; ${ }^{2}$ Department of Oncology, Lund University Hospital, Lund SE-22 I 85, Sweden; ${ }^{3}$ Department of Orthopedics, Lund University Hospital, Lund SE-22I 85, Sweden; ${ }^{4}$ Department of Orthopedics, Karolinska Hospital, Stockholm SE-17I 76, Sweden; ${ }^{5}$ Department of Molecular Cell Biology, Leiden University Medical Center, Leiden 2300 RC, The Netherlands;

${ }^{6}$ Department of Pathology, Leiden University Medical Center, Leiden 2300 RC, The Netherlands

The initiating somatic genetic events in chordoma development have not yet been identified. Most cytogenetically investigated chordomas have displayed near-diploid or moderately hypodiploid karyotypes, with several numerical and structural rearrangements. However, no consistent structural chromosome aberration has been reported. This is the first array-based study characterising DNA copy number changes in chordoma. Array comparative genomic hybridisation $(\mathrm{aCGH})$ identified copy number alterations in all samples and imbalances affecting 5 or more out of the 21 investigated tumours were seen on all chromosomes. In general, deletions were more common than gains and no high-level amplification was found, supporting previous findings of primarily losses of large chromosomal regions as an important mechanism in chordoma development. Although small imbalances were commonly found, the vast majority of these were detected in single cases; no small deletion affecting all tumours could be discerned. However, the CDKN2A and CDKN2B loci in 9p21 were homo- or heterozygously lost in 70\% of the tumours, a finding corroborated by fluorescence in situ hybridisation, suggesting that inactivation of these genes constitute an important step in chordoma development. British Journal of Cancer (2008) 98, 434-442. doi:I 0. I038/sj.bjc.6604I 30 www.bjcancer.com

Published online II December 2007

(C) 2008 Cancer Research UK

Keywords: chordoma; array CGH; CDKN2A; genomic imbalances

Usually located along the axial skeleton, primarily in the sacrococcygeal and sphenooccipital regions, chordomas are believed to be derived from remnants of the embryonal notochord (Vujovic et al, 2006). These tumours are rare lesions accounting for about $1-4 \%$ of all primary bone sarcomas (Mirra et al, 2002). Several histological subtypes have been described; classical chordoma, which is the most common entity, chondroid chordoma, featuring regions resembling cartilage, and so-called 'dedifferentiated' chordoma, a rare subtype showing high-grade features. Histologically, chordomas are composed of physaliphorous cells expressing a particular low molecular weight cytokeratin pattern embedded in a mucomyxoid background (Mertens et al, 1994; Hazelbag et al, 1996; Dalpra et al, 1999; Scheil et al, 2001; Tallini et al, 2002). Clinically, chordomas manifest as slowly growing, locally destructive lesions with a tendency to infiltrate into adjacent tissues. Metastases are rarely encountered but because of difficulties in obtaining wide-margin resection of the primary tumour, local recurrences resulting in tissue destruction are common, eventually killing the patient.

Most cytogenetically investigated chordomas have displayed near-diploid or moderately hypodiploid karyotypes, with several

*Correspondence: Dr KH Hallor;

E-mail: Karolin.Hansen_Hallor@med.lu.se

Received 20 September 2007; revised 7 November 2007; accepted 15 November 2007; published online II December 2007 numerical and structural rearrangements (Mitelman et al, 2007). Recurrent chromosomal aberrations in chordomas, identified using G-banding, metaphase comparative genomic hybridisation (mCGH), and fluorescence in situ hybridisation (FISH), include loss of the entire or parts of chromosomes 3, 4, 10,13, and 18; loss or rearrangement of $1 \mathrm{p}$ and $9 \mathrm{p}$; and gain of chromosome 7 (Sawyer et al, 2001; Scheil et al, 2001; Tallini et al, 2002; Kuzniacka et al, 2004; Brandal et al, 2005). However, neither by mCGH nor cytogenetics has any consistent structural chromosome aberration been detected. Thus, to date there is no indication that balanced or unbalanced chromosomal exchanges leading to the creation of fusion genes are important in chordoma development.

In the present study, biopsies from classical chordomas were studied by bacterial artificial chromosome (BAC) array comparative genomic hybridisation (aCGH) and/or FISH, with the purpose of detecting possible cryptic chromosomal aberrations not previously identified.

\section{MATERIALS AND METHODS}

\section{Patients and materials}

The present study included 30 tumour samples from 26 patients ( 8 women and 18 men, median age 60 years). All tumours were diagnosed as classical chordoma and located in the sacrum $(n=20)$, coccyx $(n=4)$, or thoracic vertebrae T11-12 $(n=2)$. 
Eighteen of the tumours were primary lesions, ten were local recurrences, and two were metastases. Clinical information is presented in Table 1.

\section{Chromosome banding analysis}

Fresh tumour samples were processed for G-banding analysis as previously described (Mandahl, 2001), and karyotypes were described according to the guidelines in ISCN (1995) (Mitelman, 1995).

\section{2k BAC microarray}

Cases 1-11 were analysed using $32 \mathrm{k}$ tiling microarrays containing more than 32000 partly overlapping, individual BAC clones, generating complete coverage of the human genome. The arrays were produced at the Swegene DNA Microarray Resource Center, Department of Oncology, Lund University (http://swegene.onk.lu.se) as previously described (Jönsson et al, 2007), using BAC clones mapped to the hg17 genome build. Extraction, labelling, and hybridisation of genomic DNA from freshly frozen tumour biopsies, as well as pretreatment and washing of slides were performed as described previously (Heidenblad et al, 2006). As a control for normal copy number, a DNA pool derived from multiple healthy male donors was used (Promega, Madison, WI, USA).

\section{Mb BAC microarray}

Cases 17-26, and the respective relapse in four of these tumours, were analysed with $1 \mathrm{Mb}$ microarrays containing approximately $3500 \mathrm{BAC}$ clones spaced at about $1 \mathrm{Mb}$ density over the genome. This BAC set is distributed to academic institutions by the Welcome Trust Sanger Institute (UK) at no cost, and information regarding the full set is available at the Sanger Center mapping database site, Ensembl (http://www.ensembl.org). The clones were spotted in triplicate, and the slides used in the current study were produced at Leiden University Medical Center, as previously described (Knijnenburg et al, 2005). DNA isolation, labelling, and microarray hybridisation were performed as described previously (Rozeman et al, 2006; Knijnenburg et al, 2007).

\section{Image and data analysis}

Primary data were collected using the GenePix Pro 4.0 software (Axon Instruments Inc., Foster City, CA, USA), and the quantified data matrix was deposited into the web-based database BioArray Software Environment (BASE) (Saal et al, 2002). Following background correction using the median foreground minus the median background signal intensity for each channel, the $\log 2$ ratios were calculated for each spot. Unreliable features marked in the feature extraction software, and spots not showing signal-tonoise ratios $\geqslant 5$ for both channels, were removed. Normalisation of data was performed using the popLowess algorithm (Staaf et al, in press), with a window size of $1 \%$ and a segmentation constant of 5. Normalised data were smoothed using a three-probe moving average window with adaptive thresholds ( $1 \%$ window size, scaling factor 2) (Staaf et al, in press), to prevent smoothing artefacts and allow detection of single outlier probes (subsequently removed). Log 2 ratios for each sample and platform were segmented using a BASE implementation of CGH-Plotter (Autio et al, 2003), written in R (http://www.r-project.org/). The segmentation constant, c, was set to 9 . Segments less than 2 probes or $500 \mathrm{~kb}$ in size were removed. To facilitate cross-platform comparison, segmented data was transformed into a virtual probe set with probes spaced at $50 \mathrm{~kb}$ throughout the entire genome by associating each platform probe to its closest virtual probe. Copy number alterations were determined by comparing the segmented $\log 2$ ratios to gain/loss

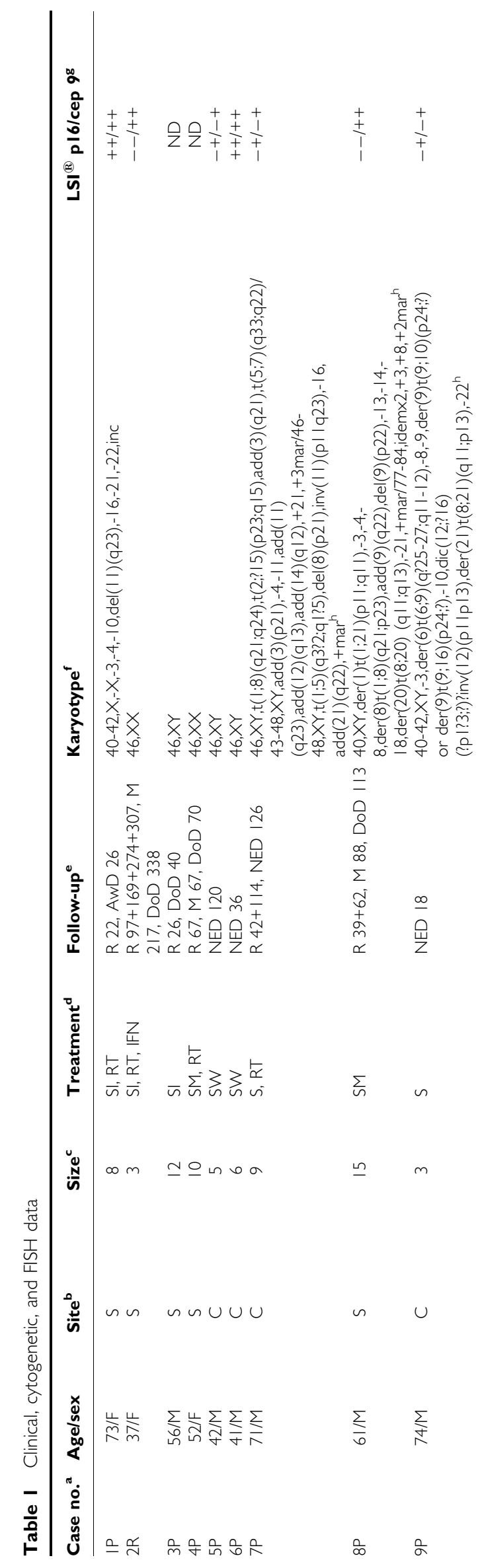


Table I (Continued)

\begin{tabular}{|c|c|c|c|c|c|c|c|}
\hline Case no. ${ }^{a}$ & Age/sex & Site $^{b}$ & Size $e^{c}$ & Treatment $^{\mathrm{d}}$ & Follow-up ${ }^{e}$ & Karyotype $^{f}$ & LSI ${ }^{\circledR}$ pl6/cep $9^{g}$ \\
\hline IOP & $60 / F$ & s & 6 & S & NED 120 & 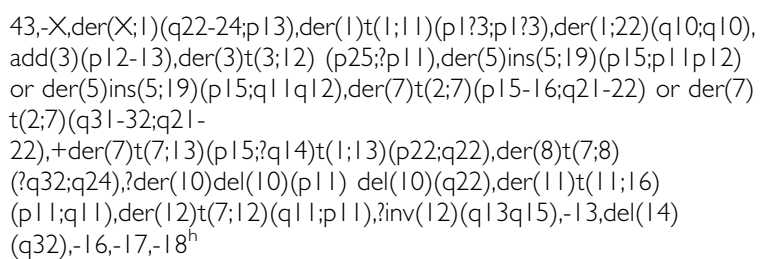 & $++/++$ \\
\hline IIP & $51 / M$ & S & 8 & $\mathrm{SI}$ & $\begin{array}{l}\text { R } 3+60+63+86+90+113 \\
\text { DoD } 118\end{array}$ & 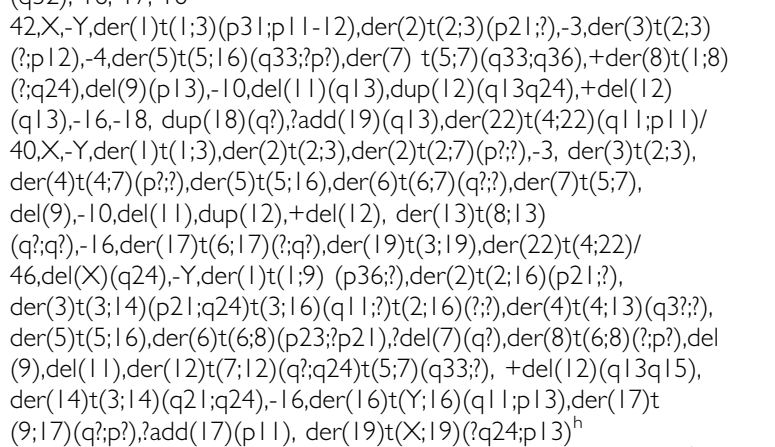 & $-+/++$ \\
\hline $12 R$ & 70/M & $\mathrm{T} 12$ & 5 & S, RT & $R 12+23, A w D 61$ & $40-44, X Y,-1, \operatorname{der}(3) t(1 ; 3)(\mathrm{q}|| ; \mathrm{q}||), ?-4, \operatorname{der}(9) \mathrm{t}(9 ; \mid 4)(\mathrm{p}|| ; p \mid 3),-22^{\mathrm{h}}$ & $-+/++$ \\
\hline $13 R$ & $7 \mid / M$ & TII & 5 & $\mathrm{SI}, \mathrm{RT}$ & R 6. DoD 50 & $47-48, X Y,+2, \operatorname{inv}(9)(p|| q \mid 2) c,+13,-14,-16,-16,+2 \mathrm{mar}$ (primary tumour) ${ }^{\mathrm{h}}$ & $++/++$ \\
\hline I4P & 50/M & $\mathrm{s}$ & 8 & SM & NED 22 & $43-46, X Y,-3,+12,-13, \operatorname{add}(2 \mid)(q ? 21),+\operatorname{der}(?) t(? ; 1)(? ; q 2 \mid)$ & $++/++$ \\
\hline I5R & $63 / M$ & S & $?$ & SW & R I57, NED 200 & $\begin{array}{l}39-40, X Y, t(1 ; 20)(q|2 ; q| 3),-3, t(6 ; 9)(q 27 ; q 13),-10,-14,-18,-21,-22 / 36- \\
40, X Y,-3, t(6 ; 9),-10,-14,-18, \operatorname{der}(20) \mathrm{t}(1 ; 20),-21,-22\end{array}$ & $-+/++$ \\
\hline I6M & $32 / M$ & S & $?$ & $\mathrm{~S}, \mathrm{RT}$ & R, M, DoD 285 & 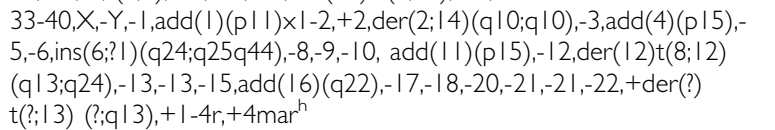 & $++/++$ \\
\hline 17R & 59/M & $\mathrm{s}$ & ? & SW & NED 64 & ND & ND \\
\hline $18 \mathrm{P}$ & $85 / F$ & $\mathrm{~s}$ & ? & $\mathrm{SI}$ & DoC 20 & ND & ND \\
\hline 19P & $66 / M$ & $\mathrm{~s}$ & ? & SM & AwD 48 & ND & ND \\
\hline $20 P$ & 68/F & $\mathrm{s}$ & ? & SW & M 48, AwD 48 & ND & ND \\
\hline $2 I P$ & $50 / M$ & S & $?$ & SM & R 12, AwD 98 & ND & ND \\
\hline $2 I R$ & & & & SW, RT & & ND & ND \\
\hline $\begin{array}{l}22 \mathrm{P} \\
22 \mathrm{M}\end{array}$ & $52 / F$ & s & $?$ & SM & M 36, AWD 48 & 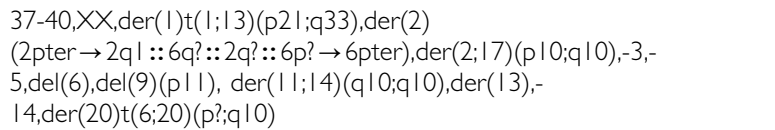 & ND \\
\hline $23 \mathrm{P}$ & 70/M & S & ? & $\mathrm{SI}, \mathrm{RT}$ & LTF & ND & ND \\
\hline $\begin{array}{l}24 \mathrm{P} \\
24 \mathrm{R}\end{array}$ & $66 / M$ & S & $?$ & $\begin{array}{l}\text { SM, } \\
\text { SW, RT }\end{array}$ & R 36, NED 52 & ND & ND \\
\hline $25 R$ & $57 / M$ & $\mathrm{~s}$ & ? & $\mathrm{SI}, \mathrm{RT}$ & M, LTF & ND & ND \\
\hline $\begin{array}{l}26 R I \\
26 R 2\end{array}$ & $42 / F$ & S & $?$ & $\begin{array}{l}\mathrm{SI}, \mathrm{RT} \\
\mathrm{SI}\end{array}$ & R 204, AwD 210 & ND & ND \\
\hline
\end{tabular}

$\mathrm{aCGH}=$ array comparative genomic hybridisation; $C O B R A=$ combined binary ratio; $F=$ female; $F I S H=$ fluorescence in situ hybridisation; $M=$ male. ${ }^{a} P=$ primary tumour; $R=$ local recurrence; $M=$ metastasis. ${ }^{b} S=$ sacrum;

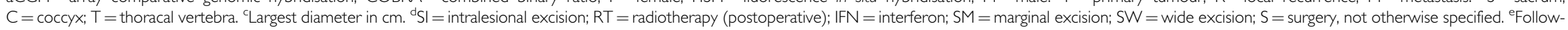
up in months. $R=$ local recurrence (time to local recurrence in months specified when known); $A w D=$ alive with disease; $M=$ metastasis (time to metastasis in months specified when known); DoD = dead of disease; NED = no evidence of disease; $\mathrm{DoC}=$ dead of other causes; $\mathrm{LTF}=$ lost to follow-up. 'Karyotypes based on G-banding, COBRA-FISH, and aCGH results. $\mathrm{ND}=$ not determined. ${ }^{\mathrm{g}}(+)$ and $(-)$ indicate presence and absence, respectively, of signals from the probe. ND = not determined. 'Karyotypes previously published (Mertens et al, 1994; Kuzniacka et al, 2004). 


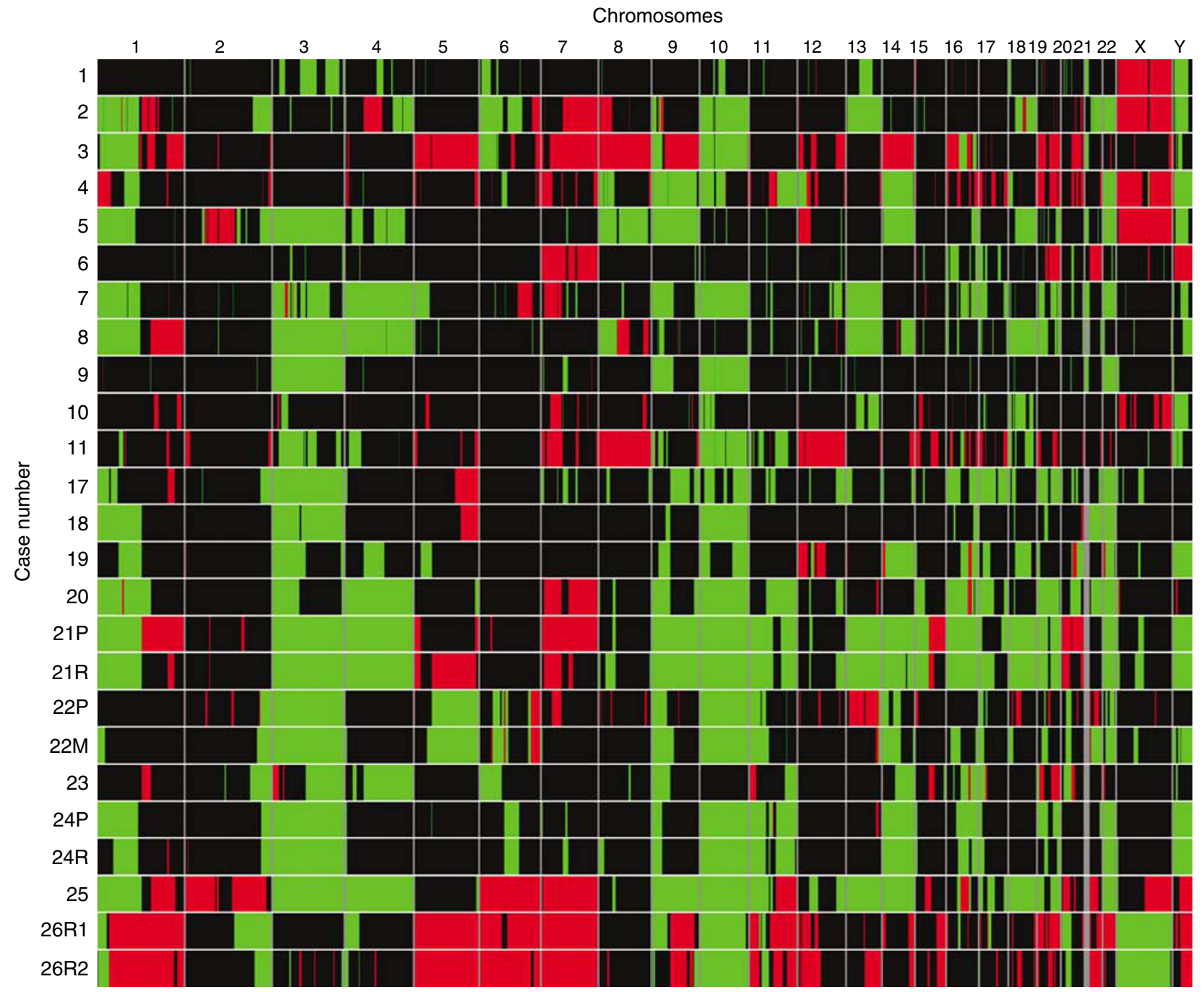

Figure I Genomic imbalances detected in individual samples. Gains (red) and losses (green) of genomic material were detected in all samples investigated by array comparative genomic hybridisation $(\mathrm{aCGH})$. Each row corresponds to a separate sample and each column represents an individual chromosome. The respective relapse was investigated in four cases, and samples from the same tumour showed very similar patterns of aberrations. However, although the pattern of aberrations was almost identical, a few aberrations escaped detection in one of the samples from the same tumour. This was primarily found for low copy number changes and can most probably be explained by normal cell contamination (See online version for colour figure.).

thresholds obtained by an adaptive scaling method (Staaf et al, in press), using a window size of $2 \%$ and a scaling factor of 2 . Segments above gain threshold were set to 1, below loss threshold as -1 , and in-between as 0 .

Microarray data are available at GEO (http://www.ncbi.nlm.nih. gov/geo/), using the accession number GSE9023.

\section{Fluorescence in situ hybridisation}

Nine of the tumours analysed with $32 \mathrm{k}$ aCGH and an additional five chordomas lacking material for aCGH (cases 12-16) were analysed with FISH (Table 1) as described (Dahlén et al, 2003). The status of the gene CDKN2A ( $p 16)$ was investigated using the commercially available LSI $^{\circledR}$ p16, a probe specific for the centromere of chromosome 9 (cep 9), and whole-chromosome painting probes specific for selected chromosomes (Vysis, Downers Grove, IL, USA). Whole-chromosome painting probes were used to discriminate tumour and normal cells. To determine presence/ absence of CDKN2A, a minimum of three tumour cells displaying concordant LSI p16 status was required.

\section{RESULTS}

The karyotypes, based on G-banding, multicolour combined binary ratio (COBRA)-FISH and DNA copy number profiles, are presented in Table 1. Five out of the nine previously unpublished karyotypes displayed a normal chromosome complement, and four showed a near-diploid chromosome number with multiple chromosomal imbalances. All cases, including the five tumours with normal Gbanding karyotypes, displayed genomic imbalances upon aCGH analysis (Figure 1). Changes affecting five or more of the samples were identified on all chromosomes (Figure 2, Table 2), and in each case, one-third (median 0.33 , range: $0.13-0.73$ ) of the investigated clones showed copy number alterations. There was a median of 23 deletions resulting in, on average, loss of $678 \mathrm{Mb}$ per tumour. The corresponding figures for the gained regions were significantly smaller, with a median number of 10 gained regions and a total size of $177 \mathrm{Mb}$ per tumour $(P<0.01$, Mann - Whitney $U$-test $)$. High-level amplifications were not detected in any case, and no small deletion was identified throughout all samples although recurrent narrow deletions $(\sim 1 \mathrm{Mb})$ were found on several chromosomes. 


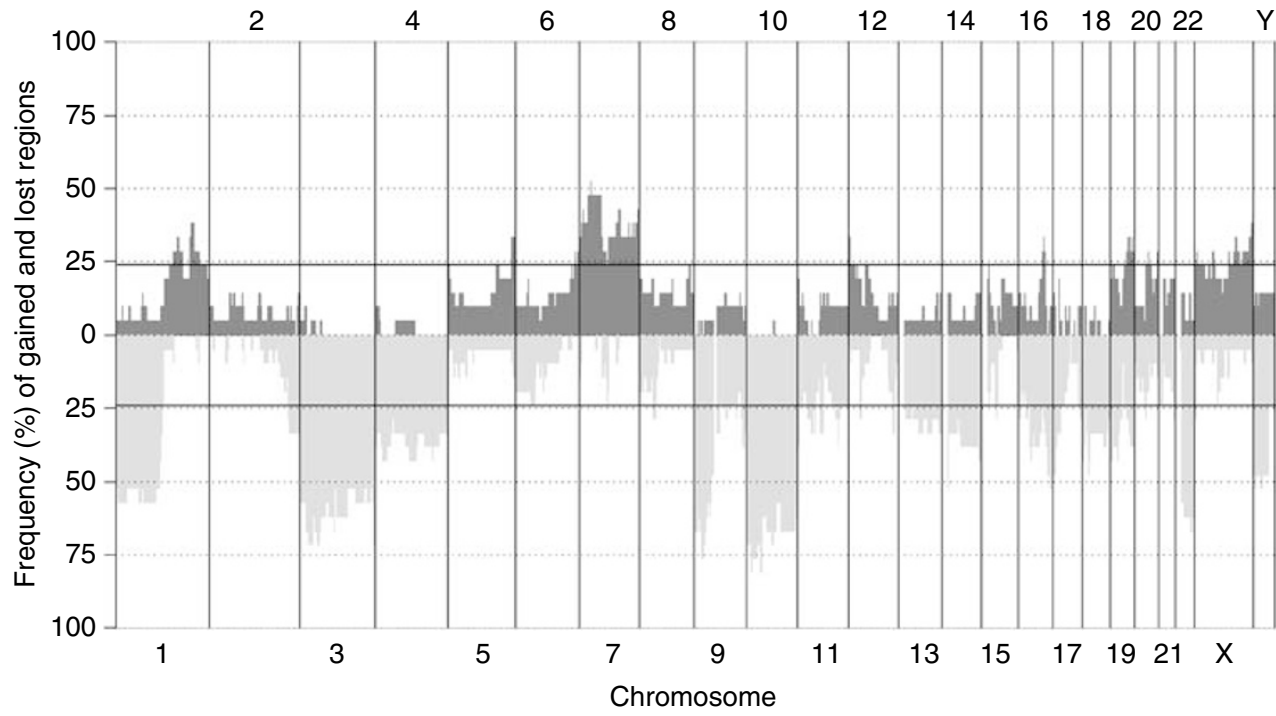

Figure 2 Frequency of DNA copy number changes detected by array comparative genomic hybridisation (aCGH) in 21 chordomas. Copy number alterations present in five or more of the samples were identified on all chromosomes. The number of deletions was larger than the number of gains, and the size of the deleted regions was significantly larger than the gained regions. The genomic positions of the imbalances are presented in Table 2.

Table 2 aCGH findings in 21 chordomas

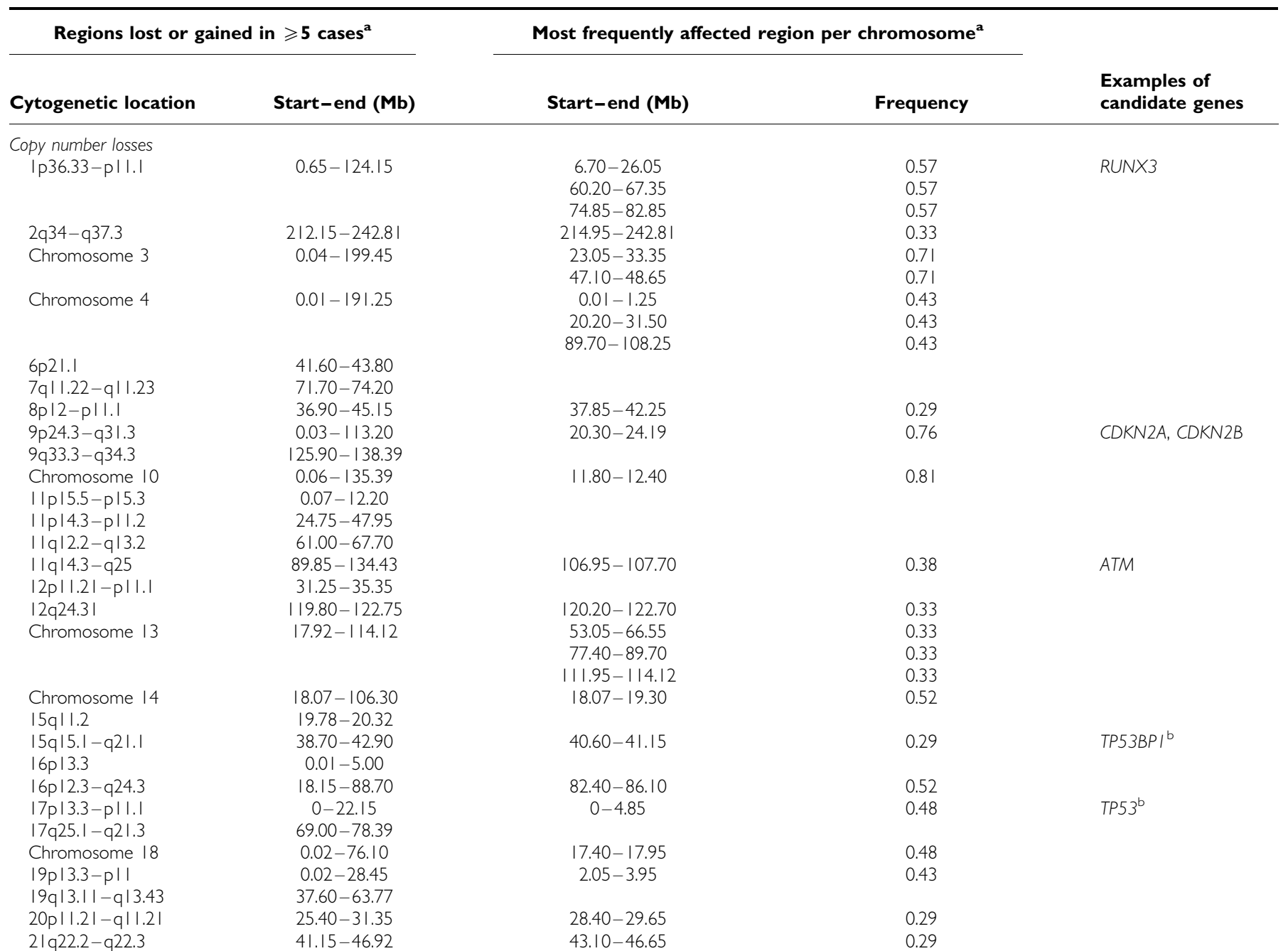


Table 2 (Continued)

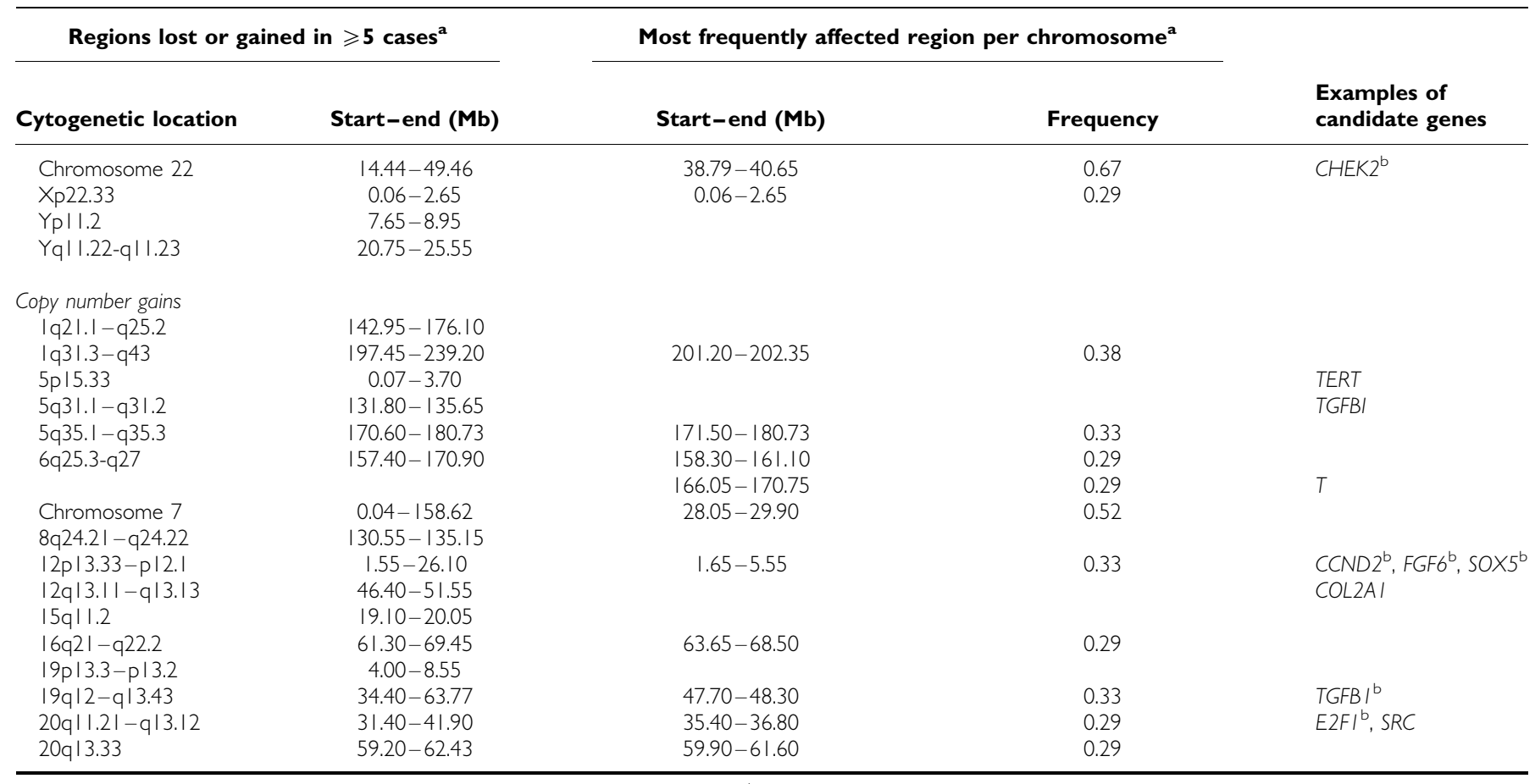

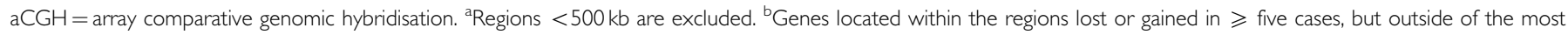
frequently affected region.

Homozygous deletions were found on chromosomes 8, 9, and 18. The losses on chromosomes 8 and 18 were found in one case each, and the affected regions (7.04-7.84 and 33.45-35.04 Mb, respectively) did not harbour any obvious candidate genes. The homozygous deletions on chromosome 9 were located in the region $20.44-27.96 \mathrm{Mb}$, covering the CDKN2A locus in chromosomal subband 9p21.3. By aCGH, cases $4,5,7,9,11$, and 19-26 showed a heterozygous deletion and cases 2,3 , and 8 displayed a homozygous loss. These findings were confirmed by FISH in nine cases (Figure 3; Table 1). In addition, this region was investigated in five samples lacking material for aCGH. Two of these showed a heterozygous deletion of LSI p16. Thus, of a total of 26 tumours investigated, $15(58 \%)$ displayed a heterozygous deletion of the region covering the CDKN2A locus, and 3 (12\%) showed a homozygous deletion (Table 1).

In four of the tumours, also the respective relapse was analysed with the $1 \mathrm{Mb}$ microarrays. The DNA profiles of the samples from the same tumour were highly similar (Figure 1), and the relapses were excluded from further analyses.

The number and the size of the aberrations were not significantly different in the six tumours that later metastasised, compared with the rest of the tumours. Neither was there any chromosomal aberration that could be specifically linked to the group of tumours that developed metastases.

\section{DISCUSSION}

In the present study, aberrant DNA copy number profiles were detected in 21 chordomas. Primarily losses of large chromosomal regions were found; high-level amplifications were not detected, and there was no small deletion common to all samples. However, frequent small deletions were found on several chromosomes. Whether loss of these regions results in functional inactivation of genes important in tumour development or reflects normal copy number variation remains to be elucidated.
Overall, the results were highly consistent with previous cytogenetic and mCGH findings, confirming that chordoma is a genetically heterogeneous tumour lacking apparent recurrent structural rearrangements, but demonstrating frequent imbalances of large chromosomal regions.

\section{Frequently deleted regions}

Deletions affecting five or more samples were found on all chromosomes, except chromosome 5, and included loss of the entire or major parts of chromosome arm $1 \mathrm{p}$ and chromosomes 3, $4,9,10,13,14,16,18,19$, and 22 (Figure 2; Table 2).

Loss or rearrangement of $1 \mathrm{p} 36$ is a common finding in sporadic chordoma, and this region has also been associated with hereditary chordoma (Mertens et al, 1994; Dalpra et al, 1999; Miozzo et al, 2000; Riva et al, 2003; Kuzniacka et al, 2004). By loss of heterozygosity analysis, the $1 \mathrm{p} 36.31-\mathrm{p} 36.13$ region was linked to familial as well as sporadic chordoma (Miozzo et al, 2000), and the same group later delimited the region for sporadic chordoma development to 1 p36.13 (Riva et al, 2003). In the present study, a minimally deleted region in $1 \mathrm{p} 36.31-\mathrm{p} 36.11$ was found. This region contains several genes including $R U N X 3$, a transcription factor, which has been shown to be frequently deleted or transcriptionally silenced in a number of cancers, and it has been suggested to encode an important tumour suppressor (Blyth et al, 2005). Furthermore, this gene has been shown to be implicated in chondrocyte maturation, providing a biological link to the development of chordoma (Soung et al, 2007).

Frequent loss of chromosome arm $9 \mathrm{p}$ has previously been described in chordomas (Scheil et al, 2001; Kuzniacka et al, 2004; Brandal et al, 2005), and particularly, the region covering the CDKN2A ( $p 16$ and $p 14)$ and $C D K N 2 B(p 15)$ loci in chromosomal band 9p21 has been shown to be deleted in many tumour types (Gil and Peters, 2006), also in chondrosarcoma (van Beerendonk et al, 2004). Here, we provide further evidence that loss of this region is an important event also in chordomas, with $70 \%$ of the 

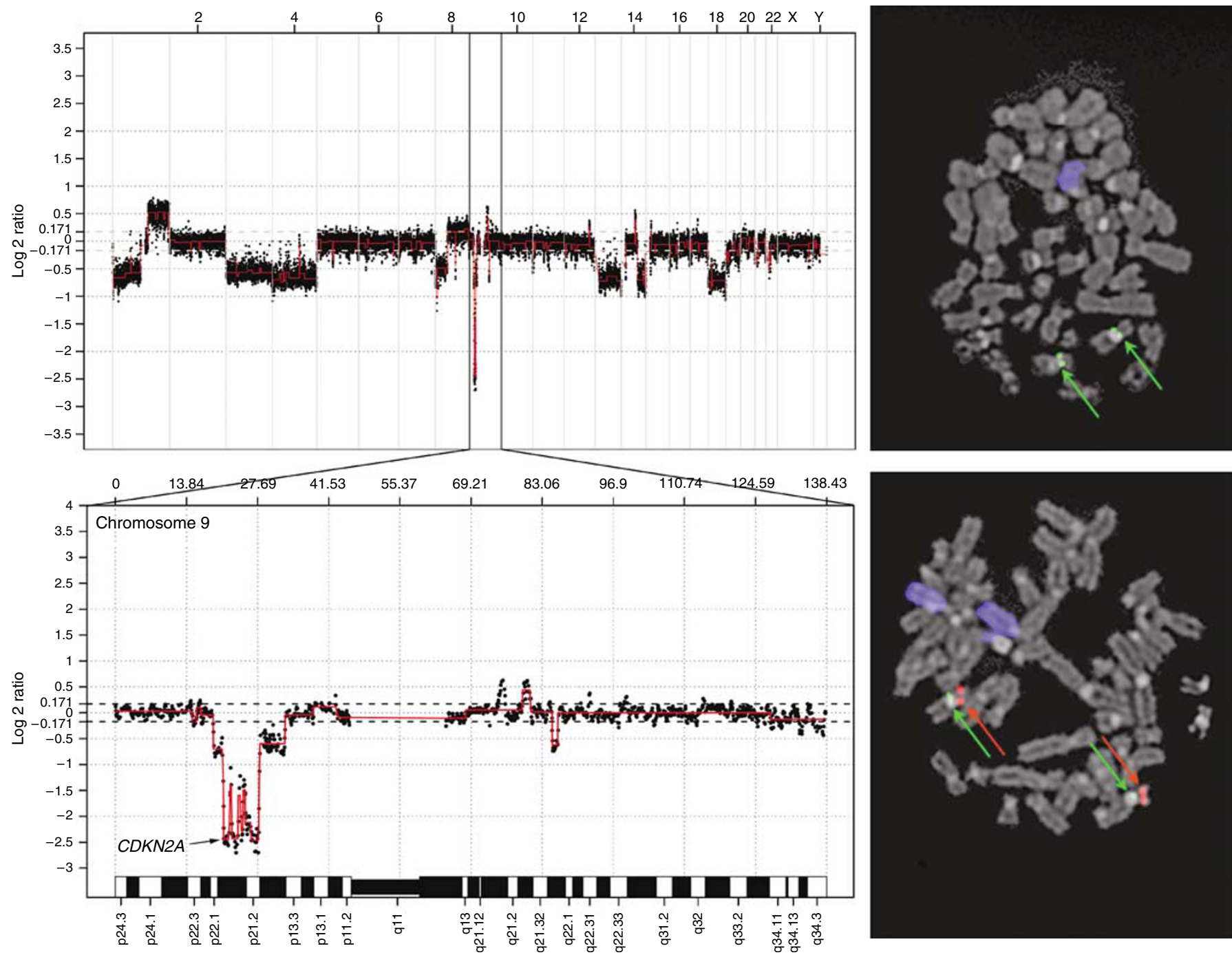

Figure 3 DNA copy number changes in a representative chordoma. Genomic profile of case 8 analysed using 32k array comparative genomic hybridisation (aCGH; top left). Tumour/reference log 2 ratios are displayed as the moving average of three consecutive bacterial artificial chromosome (BAC) clones, and individual chromosomes are separated by vertical bars. The profile demonstrates multiple imbalances, e.g., loss of chromosome I 3 and homozygous deletion of CDKN2A ( $/ 6$ ) on chromosome 9 (bottom left). Fluorescence in situ hybridisation (FISH) analysis of the same case displays loss of chromosome 13 (blue) and homozygous deletion of CDKN2A ( $p / 6$ ) (top right). For comparison, a normal cell shows two chromosomes I 3 and two normal chromosomes 9, with centromere of chromosome 9 (cep 9) and LSI pl6 indicated in green and red, respectively (bottom right) (See online version for colour figure.).

tumours showing deletion of this region. Interestingly, in addition to the three reported cases with a homozygous deletion, three more cases in fact showed homozygous loss of the clone RP11-467K20 (cases 4,5 , and 11). This clone covers exon 1 of $C D K N 2 A$ (isoform 4) as well as the entire $C D K N 2 B$, suggesting that additional deletions affecting this region would have been identified using arrays with even higher resolution. Noteworthy, the group of six patients with potential homozygous loss of $C D K N 2 A$ and $C D K N 2 B$ contained all five patients, investigated by aCGH, who died from their disease. Furthermore, although no particular aberration could be discerned distinguishing metastasising from nonmetastasising tumours using aCGH, deletion of this locus was found in all tumours that metastasised compared to two-thirds of the nonmetastasising tumours (data not shown). Taken together, our results are in agreement with a recent study in which immunohistochemic staining for the CDKN2A protein in chordoma consistently yielded negative results (Naka et al, 2005), and indicate that inactivation of CDKN2A may be important for chordoma development, although not tumour-type specific.
In this context, it could be noted that loss of heterozygosity previously has been found for the $R B 1$ gene in chordoma (Eisenberg et al, 1997), supporting a fundamental role for the RB1-signalling pathway in chordoma oncogenesis. In line with these findings, the TP53 pathway also seems to be frequently affected in chordoma; both TP53 and TP53BP1 were recurrently deleted. Moreover, the CHEK2 gene is located in a region on chromosome 22, which was lost in 13 of the cases. CHEK2 is considered a tumour suppressor and mutations of CHEK2 have been implicated in the pathogenesis of various types of familial as well as sporadic tumours, for example, the malignant bone tumour osteosarcoma (Miller et al, 2002). In the minimally deleted region on chromosome 11, which was lost in eight cases, ATM is located. The corresponding protein is believed to be important for cell response to DNA damage and for genome stability by regulating signalling pathways involving CHEK2, TP53, and a variety of additional cell cycle checkpoint proteins (Lavin and Kozlov, 2007).

Although the present study confirmed a frequent loss of chromosomes $3,4,10,13$, and 18 , no obvious candidate tumour 
suppressors were found in the minimal deleted regions. Thus, either these chromosomes harbour several genes of importance for tumour development, requiring large regions to be deleted to obtain a tumourigenic effect, or the functional inactivation is preferentially achieved through large rearrangements. The same is probably true for chromosomes 14,16 , and 19, which previously have not been reported to be frequently deleted chromosomes in chordoma.

\section{Frequently gained regions}

Generally, gains were smaller than losses and not as frequently observed. However, as shown in previous studies, gain of chromosome 7 is a common finding in chordomas (Sawyer et al, 2001; Scheil et al, 2001; Kuzniacka et al, 2004; Brandal et al, 2005). The most common gain, detected in more than half of the samples, was found in 7p15.1. This region harbours the genes CREB5, CPVL, and CHN2, none of which has any obvious role in chordoma development. Hence, it is likely that gain of large regions of this chromosome is required for tumour formation.

The gene expression pattern in chordoma has in a recent study been shown to cluster with cartilaginous tumours, particularly chondrosarcomas (Henderson et al, 2005), although the cDNA expression patterns clearly differ from other reported studies on chondrosarcoma as well as other cartilaginous tumours (Rozeman et al, 2005; Romeo et al, 2007). The study of Henderson et al (2005), however, suggests that genes involved in cartilage development might be of importance for chordoma oncogenesis. In line with these findings, the locus for TGFBI on chromosome 5 was gained in five of the cases in the present study. The corresponding protein product has been suggested to be involved in cartilage development by stimulating the growth of prechondrogenic cells (Ohno et al, 2002). Similarly, SOX5 is a protein believed to play an essential role in chondrocyte differentiation, and five cases displayed gain of the region on chromosome arm $12 \mathrm{p}$, which harbours the SOX5 gene (Lefebvre et al, 2001). Importantly, a transcription factor known as brachyury was demonstrated to be exclusively expressed in chordoma (Vujovic et al, 2006), which ends the long-lasting chondroid-chordoid dilemma (Romeo and Hogendoorn, 2006). The gene encoding brachyury $(T)$ is located in band $6 \mathrm{q} 27$, and the chromosomal region covering this gene was gained in six of the cases. Furthermore, none of the samples showed deletions that could have affected this gene.

\section{REFERENCES}

Autio R, Hautaniemi S, Kauraniemi P, Yli-Harja O, Astola J, Wolf M, Kallioniemi A (2003) CGH-Plotter: MATLAB toolbox for CGH-data analysis. Bioinformatics 19: 1714-1715

Blyth K, Cameron ER, Neil JC (2005) The RUNX genes: gain or loss of function in cancer. Nat Rev Cancer 5: 376-387

Bovee JVMG, Sciot R, Dal Cin P, Debiec-Rychter M, van Zelderen-Bhola SL, Cornelisse CJ, Hogendoorn PCW (2001) Chromosome 9 alterations and trisomy 22 in central chondrosarcoma: a cytogenetic and DNA flow cytometric analysis of chondrosarcoma subtypes. Diagn Mol Pathol 10: 228-235

Brandal P, Bjerkehagen B, Danielsen H, Heim S (2005) Chromosome 7 abnormalities are common in chordomas. Cancer Genet Cytogenet 160: 15-21

Dahlén A, Debiec-Rychter M, Pedeutour F, Domanski HA, Höglund M, Bauer HCF, Rydholm A, Sciot R, Mandahl N, Mertens F (2003) Clustering of deletions on chromosome 13 in benign and low-malignant lipomatous tumors. Int J Cancer 103: 616-623

Dalpra L, Malgara R, Miozzo M, Riva P, Volonte M, Larizza L, Fuhrman Conti AM (1999) First cytogenetic study of a recurrent familial chordoma of the clivus. Int J Cancer 81: 24-30

Eisenberg MB, Woloschak M, Sen C, Wolfe D (1997) Loss of heterozygosity in the retinoblastoma tumor suppressor gene in skull base chordomas and chondrosarcomas. Surg Neurol 47: 156-160

\section{CONCLUSIONS}

The DNA copy number profiles were consistent with previous cytogenetic and mCGH findings. However, many of the DNA copy number abnormalities identified in the present study would not have been detected using mCGH, due to the small size of the imbalances. In addition, even though several of the samples analysed herein displayed a normal karyotype upon G-banding, aCGH detected chromosomal aberrations in all cases. This is most likely explained by a growth advantage in vitro for normal cell populations. Thus, although it has been suggested that chromosomal abnormalities in chordomas represent late events in tumour progression (Sawyer et al, 2001; Sandberg and Bridge, 2003), the results in the current study indicate that all chordomas harbour chromosomal imbalances.

In agreement with previous studies (Scheil et al, 2001), recurrent tumours did not show more chromosomal abnormalities than the respective primary lesions; in fact, the DNA profiles were almost identical. Neither did the DNA copy number pattern differ between tumours that developed metastases and the nonmetastasising tumours. Thus, although the number of cases studied was low, there was no obvious correlation between the number, size, or location of the aberrations detected and the clinicopathologic features.

We were not able to distinguish any chordoma-specific markers useful for diagnosis. In fact, many of the findings in this study, such as loss of $1 \mathrm{p} 36,9 \mathrm{p}$, and $10 \mathrm{p}$ and gain of $7 \mathrm{p}$ are abnormalities previously detected in other bone tumours, for example, chondrosarcomas (Bovee et al, 2001; Sandberg and Bridge, 2003). Nonetheless, the characterisation of DNA copy numbers in chordoma provides important information about the genetic basis of chordoma development, and clinically important aberrations will hopefully emerge from future studies when the copy number alterations can be associated with gene expression profiles.

\section{ACKNOWLEDGEMENTS}

This work was supported by the Swedish Cancer Society. The Department of Clinical Genetics, Lund University Hospital and Department of Pathology, Leiden University Medical Center are partners of the EuroBoNeT consortium, a network of excellence granted by the European Commission for studying the pathology and genetics of bone tumours.
Gil J, Peters G (2006) Regulation of the INK4b-ARF-INK4a tumour suppressor locus: all for one or one for all. Nat Rev Mol Cell Biol 7: $667-677$

Hazelbag HM, Mooi WJ, Fleuren GJ, Hogendoorn PCW (1996) Chainspecific keratin profile of epithelioid soft-tissue sarcomas. Appl Immunohistochem 4: 176-183

Heidenblad M, Hallor KH, Staaf J, Jönsson G, Borg A, Höglund M, Mertens F, Mandahl N (2006) Genomic profiling of bone and soft tissue tumors with supernumerary ring chromosomes using tiling resolution bacterial artificial chromosome microarrays. Oncogene 25: 7106-7116

Henderson SR, Guiliano D, Presneau N, McLean S, Frow R, Vujovic S, Anderson J, Sebire N, Whelan J, Athanasou N, Flanagan AM, Boshoff C (2005) A molecular map of mesenchymal tumors. Genome Biol 6: R76

Jönsson G, Staaf J, Olsson E, Heidenblad M, Vallon-Christersson J, Osoegawa K, de Jong P, Oredsson S, Ringner M, Höglund M, Borg $\AA$ (2007) High-resolution genomic profiles of breast cancer cell lines assessed by tiling BAC array comparative genomic hybridization. Genes Chromosomes Cancer 46: 543-558

Knijnenburg J, Szuhai K, Giltay J, Molenaar L, Sloos W, Poot M, Tanke HJ, Rosenberg C (2005) Insights from genomic microarrays into structural chromosome rearrangements. Am J Med Genet A 132: 36-40 
Knijnenburg J, van der Burg M, Tanke HJ, Szuhai K (2007) Optimized amplification and fluorescent labeling of small cell samples for genomic array-CGH. Cytometry A 71: 585-591

Kuzniacka A, Mertens F, Strömbeck B, Wiegant J, Mandahl N (2004) Combined binary ratio labeling fluorescence in situ hybridization analysis of chordoma. Cancer Genet Cytogenet 151: 178-181

Lavin MF, Kozlov S (2007) ATM activation and DNA damage response. Cell Cycle 6: $931-942$

Lefebvre V, Behringer RR, de Crombrugghe B (2001) L-Sox5, Sox6 and Sox9 control essential steps of the chondrocyte differentiation pathway. Osteoarthritis Cartilage 9(Suppl A): S69-S75

Mandahl N (2001) Methods in solid tumor cytogenetics. In Human Cytogenetics: Malignancy and Acquired Abnormalities, Rooney DE (ed) 3rd edn. pp 165-203. New York: Oxford University Press

Mertens F, Kreicbergs A, Rydholm A, Willén H, Carlén B, Mitelman F, Mandahl N (1994) Clonal chromosome aberrations in three sacral chordomas. Cancer Genet Cytogenet 73: 147-151

Miller CW, Ikezoe T, Krug U, Hofmann WK, Tavor S, Vegesna V, Tsukasaki K, Takeuchi S, Koeffler HP (2002) Mutations of the CHK2 gene are found in some osteosarcomas, but are rare in breast, lung, and ovarian tumors. Genes Chromosomes Cancer 33: 17-21

Miozzo M, Dalpra L, Riva P, Volonta M, Macciardi F, Pericotti S, Tibiletti MG, Cerati M, Rohde K, Larizza L, Fuhrman Conti AM (2000) A tumor suppressor locus in familial and sporadic chordoma maps to $1 \mathrm{p} 36$. Int J Cancer 87: 68-72

Mirra JM, Nelson SD, Della Rocca C, Mertens F (2002) Notochordal tumours. In Pathology and Genetics of Tumours of Soft Tissue and Bone, Fletcher CDM, Unni KK, Mertens F (eds) pp 315-317. Lyon: IARC Press

Mitelman F (ed) (1995) ISCN (1995): An International System for Human Cytogenetic Nomenclature. Basel: S Karger

Mitelman F, Johansson B, Mertens F (eds) (2007) Mitelman Database of Chromosome Aberrations in Cancer. http://cgap.nci.nih.gov/Chromosomes/ Mitelman

Naka T, Boltze C, Kuester D, Schulz TO, Schneider-Stock R, Kellner A, Samii A, Herold C, Ostertag H, Roessner A (2005) Alterations of $\mathrm{G}_{1}-\mathrm{S}$ checkpoint in chordoma: the prognostic impact of p53 overexpression. Cancer 104: 1255 - 1263

Ohno S, Doi T, Tsutsumi S, Okada Y, Yoneno K, Kato Y, Tanne K (2002) RGD-CAP ((beta)ig-h3) is expressed in precartilage condensation and in prehypertrophic chondrocytes during cartilage development. Biochim Biophys Acta 1572: 114-122

Riva P, Crosti F, Orzan F, Dalpra L, Mortini P, Parafioriti A, Pollo B, Fuhrman Conti AM, Miozzo M, Larizza L (2003) Mapping of candidate region for chordoma development to 1 p36.13 by $\mathrm{LOH}$ analysis. Int $J$ Cancer 107: $493-497$

Romeo S, Hogendoorn PCW (2006) Brachyury and chordoma: the chondroid - chordoid dilemma resolved? J Pathol 209: 143 - 146

Romeo S, Oosting J, Rozeman LB, Hameetman L, Taminiau AHM, CletonJansen AM, Bovee JVMG, Hogendoorn PCW (2007) The role of noncartilage-specific molecules in differentiation of cartilaginous tumors: lessons from chondroblastoma and chondromyxoid fibroma. Cancer 110: $385-394$

Rozeman LB, Hameetman L, van Wezel T, Taminiau AHM, Cleton-Jansen AM, Hogendoorn PCW, Bovee JVMG (2005) cDNA expression profiling of chondrosarcomas: Ollier disease resembles solitary tumours and alteration in genes coding for components of energy metabolism occurs with increasing grade. J Pathol 207: 61-71

Rozeman LB, Szuhai K, Schrage YM, Rosenberg C, Tanke HJ, Taminiau AHM, Cleton-Jansen AM, Bovee JVMG, Hogendoorn PCW (2006) Array-comparative genomic hybridization of central chondrosarcoma: identification of ribosomal protein S6 and cyclin-dependent kinase 4 as candidate target genes for genomic aberrations. Cancer 107: $380-388$

Saal LH, Troein C, Vallon-Christersson J, Gruvberger S, Borg A, Peterson C (2002) BioArray Software Environment (BASE): a platform for comprehensive management and analysis of microarray data. Genome Biol 3: software0003.1-0003.6

Sandberg AA, Bridge JA (2003) Updates on the cytogenetics and molecular genetics of bone and soft tissue tumors: osteosarcoma and related tumors. Cancer Genet Cytogenet 145: 1-30

Sawyer JR, Husain M, Al-Mefty O (2001) Identification of isochromosome $1 \mathrm{q}$ as a recurring chromosome aberration in skull base chordomas: a new marker for aggressive tumors? Neurosurg Focus 10: 1-6

Scheil S, Bruderlein S, Liehr T, Starke H, Herms J, Schulte M, Möller P (2001) Genome-wide analysis of sixteen chordomas by comparative genomic hybridization and cytogenetics of the first human chordoma cell line, U-CH1. Genes Chromosomes Cancer 32: 203-211

Soung DY, Dong Y, Wang Y, Zuscik MJ, Schwarz EM, O’Keefe RJ, Drissi H (2007) Runx3/AML2/Cbfa3 regulates early and late chondrocyte differentiation. J Bone Miner Res 22: $1260-1270$

Staaf J, Jönsson G, Ringner M, Vallon-Christersson J (2007) Normalization of array-CGH data: influence of copy number imbalances. $B M C$ Genomics 8: 382; e-pub ahead of print 22 October 2007

Tallini G, Dorfman H, Brys P, Dal Cin P, De Wever I, Fletcher CDM, Jonson K, Mandahl N, Mertens F, Mitelman F, Rosai J, Rydholm A, Samson I, Sciot R, Van den Berghe H, Vanni R, Willén H (2002) Correlation between clinicopathological features and karyotype in 100 cartilaginous and chordoid tumours. A report from the Chromosomes and Morphology (CHAMP) Collaborative Study Group. J Pathol 196: $194-203$

van Beerendonk HM, Rozeman LB, Taminiau AHM, Sciot R, Bovee JVMG, Cleton-Jansen AM, Hogendoorn PCW (2004) Molecular analysis of the INK4A/INK4A-ARF gene locus in conventional (central) chondrosarcomas and enchondromas: indication of an important gene for tumour progression. J Pathol 202: 359-366

Vujovic S, Henderson S, Presneau N, Odell E, Jacques TS, Tirabosco R, Boshoff C, Flanagan AM (2006) Brachyury, a crucial regulator of notochordal development, is a novel biomarker for chordomas. J Pathol 209: $157-165$ 